\title{
Heterogeneous Firms Can Always Collude on a Minimum Price*
}

\author{
Joseph E. Harrington, Jr. \\ Department of Business Economics \& Public Policy \\ The Wharton School \\ University of Pennsylvania
}

8 November 2015

\begin{abstract}
When firms are heterogeneous, there may not exist a common collusive price that raises all firms' profits. However it is shown that there always exists a common minimum price that raises all firms' profits.

JEL Code: L1, L4

Keywords: Collusion, Firm Heterogeneity, Minimum Recommended Price, Trade Associations
\end{abstract}

\section{Introduction}

In practice, one of the primary challenges faced by firms desiring to collude is that they are often highly asymmetric. Firms can have different products and costs and this manifests itself in terms of different prices and quantities under competition. The stability of collusion then depends on finding a collusive outcome (and a strategy) such that all of these asymmetric firms find it incentive compatible to adhere to it. At a minimum, each firm's profit under collusion must exceed that which it earned when firms were competing. If firms can coordinate on any price vector then this latter condition is not a problem as there will always exist a collection of prices that makes all firms better off.

The problem that arises in practice is that agreeing to and coordinating on a different price for each firm will probably require extensive communication among firms which enhances the possibility that they will be discovered and convicted for engaging in unlawful collusion. An alternative is for firms to coordinate in a simpler manner that would require far less communication and coordination. One well-documented approach is price leadership

* Department of Business Economics \& Public Policy, The Wharton School, University of Pennsylvania, 3620 Locust Walk, Philadelphia, PA 19104, harrij@wharton.upenn.edu . The comments of a referee are gratefully acknowledged. This research has been conducted with the financial support of the National Science Foundation (SES-1148129). 
whereby a firm takes the role of price leader, selects a price, and then all firms match that price. While that will surely lead to higher profits for all firms when firms are similar in cost and demand, that is not true when firms are sufficiently different. For example, suppose firms have different prices and market shares under competition because their products appeal to different market segments and, in addition, some firms have relatively elastic firm demand (which is why they set relatively low prices). If all firms were to set the same price then those firms with more elastic demand would realize a large drop in sales and thus could be worse off than under competition. Or suppose firms have different costs. If firms coordinate on a price above the highest competitive price then the lowest-cost (and lowest-priced) firms may not find it profitable because their market share has significantly declined; and if they coordinate on a price below the highest competitive price (but above the lowest competitive price) then the highest-cost (and highest-priced) firms may not find it profitable because their margins are too small. For example, Goto and Iizuka (2014) examined an attempt by medical care providers to coordinate on the price charged for the flu vaccine and found that, at every common price, some firms would be earning lower profits than under competition.

A number of trade associations have pursued a different simple strategy to promote collusion among their members. Firms are asked to abide by a minimum price; that is, all firms charge a price at least as high as some minimum level and are otherwise unconstrained. The U.S. Department of Justice pursued a case against the Association of Retail Agents for "organizing a boycott of their members against airlines, hotels, and car rental companies who refused to adhere to ARTA's recommended minimum travel commission levels." ${ }^{1}$ The U.S. Federal Trade Commission brought a case against North Texas Specialty Physicians where, among other anti-competitive activities, it had encouraged members to reject fees below some minimum level. ${ }^{2}$ The Competition Commission of Singapore pursued a case against 16 bus operators and their trade association for colluding on the price of bus services from Singapore to Malaysia and Southern Thailand. One of the infringements was that the Express Bus Agencies Association announced a minimum selling price. ${ }^{3}$ Finally, returning to the flu vaccine case mentioned above, the medical association that orchestrated the collusion actually did so by putting forth a minimum recommended price of $\$ 38$.

The contribution of this paper is to show that, regardless of the extent of firm heterogeneity, there is always a minimum price that will make all firms better off. Consider a minimum price that lies between the lowest and the highest competitive prices. By causing the lowest-priced firms to raise their prices to this minimum, it is immediate that all of the higher-priced firms are better off. What is less clear is whether the lowest-priced firms are better off from having raised their prices. We show there always exists a minimum price such that all firms, including the lowest-priced firms, are better off. Effectively, the minimum price requirement causes the lowest-priced firms to act like Stackelberg leaders. They raise

\footnotetext{
${ }^{1}$ Anne K. Bingaman, "Recent Enforcement Actions by the Antitrust Division Against Trade Associations," 32nd Annual Symposium of the Trade Association and Antitrust Law Committee of the Bar Association of the District of Columbia, U.S. Department of Justice, Antitrust Division, April 25, 1996.

${ }^{2}$ North Texas Specialty Physicians v. Federal Trade Commission, No. 06-60023, 2008 WL 2043040 (5th Cir., May 14, 2008)

3 "The 'Honeymoon' is Over: CCS Fines 16 Coach Operators and their Trade Association SGD1.69 Million for Price Fixing," Ai Ai Wong and Ken Chia, Baker \& McKenzie, www.bakermckenzie.com/RRSingaporeHoneymoonIsOver (downloaded 11/19/14)
} 
price to satisfy the required minimum and the other firms respond by raising their prices. The latter is a first-order positive effect on the profits of the lowest-priced firms while the former is a second-order negative effect; hence, the lowest-priced firms earn higher profit.

\section{Model}

Consider $n \geq 2$ firms choosing prices where $\left(p_{1}, \ldots, p_{n}\right)$ is the price vector and firm $i$ 's profit function is $\pi_{i}\left(p_{1}, \ldots, p_{n}\right), i=1, \ldots, n$.

A1 $\pi_{i}\left(p_{1}, \ldots, p_{n}\right):[\underline{p}, \bar{p}]^{n} \rightarrow[0, \infty)$ is a bounded, twice continuously differentiable function.

A2 For all $\left(p_{1}, \ldots, p_{i-1}, p_{i+1}, \ldots, p_{n}\right) \in[\underline{p}, \bar{p}]^{n-1}, \partial \pi_{i}\left(p_{1}, \ldots, p_{i-1}, \bar{p}, p_{i+1}, \ldots, p_{n}\right) / \partial p_{i}<0$.

A3 $\partial \pi_{i}\left(p_{1}, \ldots, p_{n}\right) / \partial p_{j}>0$ for all $j \neq i$.

A4 $\partial^{2} \pi_{i}\left(p_{1}, \ldots, p_{n}\right) / \partial p_{i} \partial p_{j}>0$ for all $j \neq i$

A firm's profit is increasing in other firms' prices (A3) and prices are strategic complements (A4).

By these assumptions, there exists a non-decreasing best reply function $\phi_{i}\left(\mathbf{p}_{-i}\right)$, where $\mathbf{p}_{-i} \equiv\left(p_{1}, \ldots, p_{i-1}, p_{i+1}, \ldots, p_{n}\right)$,

$$
\phi_{i}\left(\mathbf{p}_{-i}\right)=\arg \max _{p_{i}} \pi_{i}\left(p_{1}, \ldots, p_{n}\right) .
$$

By A2, the upper bound on price is not a binding constraint in which case $\phi_{i}\left(\mathbf{p}_{-i}\right)<\bar{p}$.

By Theorem 4 of Milgrom and Roberts (1990) (hereafter referred to as MR90), these assumptions are sufficient to ensure the existence of a Nash equilibrium which we denote:

$$
\widetilde{p}_{i}(\underline{p})=\phi_{i}\left(\widetilde{p}_{1}(\underline{p}), \ldots, \widetilde{p}_{i-1}(\underline{p}), \widetilde{p}_{i+1}(\underline{p}) \widetilde{p}_{n}(\underline{p})\right) \text {, for all } i=1, \ldots, n \text {. }
$$

(For purposes of the later analysis, the dependence of equilibrium prices on the minimum price to a firm's choice set is made explicit.) There may be multiple equilibria. As shown in MR90, there exists a smallest and largest equilibrium where the order is $\geq$ component-wise. In the ensuing analysis, it is presumed that there is a unique equilibrium or, when there are multiple equilibria, there is a selection of either the smallest or largest.

When $p=0$, so firms are not constrained to set a minimum price (only that prices are non-negative), the selected equilibrium price vector is denoted:

$$
\left(p_{1}^{*}, \ldots, p_{n}^{*}\right)=\left(\widetilde{p}_{1}(0), \ldots, \widetilde{p}_{n}(0)\right) .
$$

$\left(p_{1}^{*}, \ldots, p_{n}^{*}\right)$ should be thought of as the non-collusive price vector; that is, the prices that would emerge if firms did not collude.

Thus far, assumptions do not ensure that there is an equilibrium in which all firms have positive demand. One approach at this point would be to impose more structure; for example, assume symmetric demand functions and constant marginal cost that is not too high and does not differ too much across firms. In the spirit of generality, it is instead assumed there is an interior equilibrium and it is heterogeneous.

A5 $p_{i}^{*} \in(0, \bar{p})$ and $\pi_{i}^{*} \equiv \pi_{i}\left(p_{1}^{*}, \ldots, p_{n}^{*}\right)>0, i=1, \ldots, n$.

A6 There exists $m \in\{1, \ldots, n-1\}$ such that $p_{1}^{*}=\cdots=p_{m}^{*}<p_{m+1}^{*} \leq \cdots \leq p_{n}^{*}$. 


\section{Collusion}

Now consider the infinitely repeated game with perfect monitoring for which the stage game is the game described in Section 2. As motivated in the Introduction, I will consider collusion in terms of firms required to set price at or above some agreed-upon minimum level, which is denoted $p$. As long as all firms have always priced at least as high as $\underline{p}$, each firm will continue to abide by the convention of pricing at or above $p$. If any firm prices below $p$, collusion ends and there is a return to static Nash equilibrium prices. ${ }^{4}$ More formally, the strategy is

$$
\begin{aligned}
p_{i}^{t} & =\left\{\begin{array}{l}
\widetilde{p}_{i}(\underline{p}) \text { if } p_{j}^{\tau} \geq \underline{p} \text { for all } \tau \leq t-1, \text { for all } j \\
p_{i}^{*} \text { otherwise. }
\end{array}\right. \\
t & =1,2, \ldots, i=1, \ldots, n
\end{aligned}
$$

Given that other firms' future prices are the same as long as firm $i$ prices at least as high as $p$, optimality (along the equilibrium path) requires that firm $i$ chooses the price that maximizes current profit subject to pricing at least as high as $p$. Given that must be true for all firms, it follows from the analysis of Section 2 that equilibrium requires firm $i$ to price at $\widetilde{p}_{i}(\underline{p})$. If firms' discount factors are sufficiently close to one then this strategy profile is a subgame perfect equilibrium as long as the collusive profit exceeds the static Nash equilibrium profit:

$$
\pi_{i}\left(\widetilde{p}_{1}(\underline{p}), \ldots, \widetilde{p}_{n}(\underline{p})\right)>\pi_{i}^{*}, \text { for all } i=1, \ldots, n .
$$

We now prove that there exists a minimum price whereby that is the case.

Theorem 1 There exists $\underline{p}>p_{1}^{*}$ such that $\pi_{i}\left(\widetilde{p}_{1}(\underline{p}), \ldots, \widetilde{p}_{n}(\underline{p})\right)>\pi_{i}^{*}$, for all $i=1, \ldots, n$.

Proof. The proof has three steps. First, it is shown that, for a game among only firms $m+1, \ldots, n$, Nash equilibrium prices are increasing in the prices of firms $1, \ldots, m$. Second, it is shown that if $p \in\left(p_{1}^{*}, p_{m+1}^{*}\right)$ then the equilibrium prices of firms $m+1, \ldots, n$ are strictly higher compared to $\underline{p}=0$. Third, it is shown that if $\underline{p}$ is sufficiently close to $p_{1}^{*}$ then profits are strictly higher for firms $1, \ldots, m$.

As an initial step, define Nash equilibrium for the game among firms $m+1, \ldots, n$ when $\underline{p}=0$ and they take as given prices for firms $1, \ldots, m$. For that game, $\widehat{p}_{i}\left(p_{1}, \ldots, p_{m}\right)$ denotes a Nash equilibrium price:

$$
\widehat{p}_{i}\left(p_{1}, \ldots, p_{m}\right)=\phi_{i}\left(p_{1}, \ldots, p_{m}, \widehat{p}_{m+1}\left(p_{1}, \ldots, p_{m}\right), \ldots, \widehat{p}_{n}\left(p_{1}, \ldots, p_{m}\right)\right), i=m+1, \ldots, n .
$$

By Theorem 4 of MR90, a Nash equilibrium exists. Again, any statement with regards to this equilibrium refers to the smallest or largest and the selection is assumed to be the same selection as with $\left(p_{1}^{*}, \ldots, p_{n}^{*}\right)$. Note that

$$
\widehat{p}_{i}\left(p_{1}^{*}, \ldots, p_{m}^{*}\right)=p_{i}^{*}, i=m+1, \ldots, n .
$$

By Theorem 6 of MR90, $\widehat{p}_{i}\left(p_{1}, \ldots, p_{m}\right)$ is non-decreasing in $p_{j}, j=1, \ldots, m$. In using Theorem 6 for the game among firms $m+1, \ldots, n$, we are treating $\left(p_{1}, \ldots, p_{m}\right)$ as exogenous

\footnotetext{
${ }^{4}$ The particular form of punishment is unimportant for the analysis.
} 
variables which, by our assumptions, satisfy A5' in MR90. Furthermore, if $\widehat{p}_{i}\left(p_{1}, \ldots, p_{m}\right) \in$ $(\underline{p}, \bar{p})$ then $\widehat{p}_{i}\left(p_{1}, \ldots, p_{m}\right)$ is increasing in $\left(p_{1}, \ldots, p_{m}\right)$, as I now show. If $\widehat{p}_{i}\left(p_{1}, \ldots, p_{m}\right) \in(\underline{p}, \bar{p})$ then it satisfies:

$$
\frac{\partial \pi_{i}\left(p_{1}, \ldots, p_{m}, \widehat{p}_{m+1}\left(p_{1}, \ldots, p_{m}\right), \ldots, \widehat{p}_{n}\left(p_{1}, \ldots, p_{m}\right)\right)}{\partial p_{i}}=0 .
$$

If $\mathbf{p}^{\prime \prime} \equiv\left(p_{1}^{\prime \prime}, \ldots, p_{m}^{\prime \prime}\right) \geq\left(p_{1}^{\prime}, \ldots, p_{m}^{\prime}\right) \equiv \mathbf{p}^{\prime}$ with strict inequality for at least one component then it follows from $\partial^{2} \pi_{i}\left(p_{1}, \ldots, p_{n}\right) / \partial p_{i} \partial p_{j}>0$ that

$$
\begin{aligned}
& \frac{\partial \pi_{i}\left(\mathbf{p}^{\prime \prime}, \widehat{p}_{m+1}\left(\mathbf{p}^{\prime \prime}\right), \ldots, \widehat{p}_{i-1}\left(\mathbf{p}^{\prime \prime}\right), \widehat{p}_{i}\left(\mathbf{p}^{\prime}\right), \widehat{p}_{i+1}\left(\mathbf{p}^{\prime \prime}\right), \ldots, \widehat{p}_{n}\left(\mathbf{p}^{\prime \prime}\right)\right)}{\partial p_{i}} \\
> & \frac{\partial \pi_{i}\left(\mathbf{p}^{\prime}, \widehat{p}_{m+1}\left(\mathbf{p}^{\prime}\right), \ldots, \widehat{p}_{n}\left(\mathbf{p}^{\prime}\right)\right)}{\partial p_{i}}=0 .
\end{aligned}
$$

That is, given firms $1, \ldots, m$ are pricing higher at $\mathbf{p}^{\prime \prime}$ and firm $j=m+1, \ldots, n$ (except firm $i$ ) is pricing weakly higher at $\widehat{p}_{j}\left(\mathbf{p}^{\prime \prime}\right)$, firm $i$ 's profit is increasing in its price when evaluated at its original equilibrium price $\widehat{p}_{i}\left(\mathbf{p}^{\prime}\right)$. Hence, $\widehat{p}_{i}\left(\mathbf{p}^{\prime \prime}\right)>\widehat{p}_{i}\left(\mathbf{p}^{\prime}\right)$, and this holds for all $i=m+1, \ldots, n$.

Consider a minimum price that is greater than the lowest equilibrium price and less than the next-to-lowest equilibrium price: $p_{1}^{*}<\underline{p}<p_{m+1}^{*}$. Given that $\widetilde{p}_{j}(\underline{p}) \geq \underline{p}$ by assumption then $\underline{p}>p_{j}^{*}$ implies $\widetilde{p}_{j}(\underline{p})>p_{j}^{*}, j=1, \ldots, \bar{m}$. Next note that, given that firm $j(=1, \ldots, m)$ prices higher at $\widetilde{p}_{j}(\underline{p})$, the equilibrium price for firm $i(=m+1, \ldots, n)$ in the game among firms $m+1, \ldots, n$ exceeds the original equilibrium price:

$$
\widehat{p}_{i}\left(\widetilde{p}_{1}(\underline{p}), \ldots, \widetilde{p}_{m}(\underline{p})\right)>p_{i}^{*}, i=m+1, \ldots, n .
$$

This is true because $\widehat{p}_{i}\left(p_{1}, \ldots, p_{m}\right)$ is increasing in $\left(p_{1}, \ldots, p_{m}\right),\left(\widetilde{p}_{1}(\underline{p}), \ldots, \widetilde{p}_{m}(\underline{p})\right)>\left(p_{1}^{*}, \ldots, p_{m}^{*}\right)$, and $\widehat{p}_{i}\left(p_{1}^{*}, \ldots, p_{m}^{*}\right)=p_{i}^{*}$. We then have

$$
\widehat{p}_{i}\left(\widetilde{p}_{1}(\underline{p}), \ldots, \widetilde{p}_{m}(\underline{p})\right)>p_{i}^{*}>\underline{p}, i=m+1, \ldots, n
$$

and, therefore, $\widehat{p}_{i}\left(\widetilde{p}_{1}(\underline{p}), \ldots, \widetilde{p}_{m}(\underline{p})\right)>\underline{p}$. Given that these $n-m$ firms are not constrained by the minimum price $\underline{p}$, it follows that

$$
\widetilde{p}_{i}(\underline{p})=\widehat{p}_{i}\left(\widetilde{p}_{1}(\underline{p}), \ldots, \widetilde{p}_{m}(\underline{p})\right), i=m+1, \ldots, n \text {. }
$$

Recall that $\widehat{p}_{i}\left(p_{1}, \ldots, p_{m}\right)$ is the equilibrium price in the game among firms $m+1, \ldots, n$ when $\underline{p}=0$.

In sum, at the minimum price $\underline{p} \in\left(p_{1}^{*}, p_{m+1}^{*}\right), \widetilde{p}_{i}(\underline{p}) \geq \underline{p}>p_{i}^{*}(i=1, \ldots, m)$ and $\tilde{p}_{i}(\underline{p})>p_{i}^{*}(i=m+1, \ldots, n)$. First note that firms $m+1, \ldots, n$ are earning strictly higher profit:

$$
\pi_{i}\left(\widetilde{p}_{1}(\underline{p}), \ldots, \widetilde{p}_{n}(\underline{p})\right)>\pi_{i}^{*}, i=m+1, \ldots, n .
$$

Given all rival firms are pricing higher $-\widetilde{p}_{j}(\underline{p})>p_{j}^{*}$ for all $j \neq i$ - and firm $i$ 's profit is increasing in rival firms' prices, firm $i$ 's profit is strictly higher at its original equilibrium price:

$$
\pi_{i}\left(\widetilde{p}_{1}(\underline{p}), \ldots, \widetilde{p}_{i-1}(\underline{p}), p_{i}^{*}, \widetilde{p}_{i+1}(\underline{p}), \ldots, \widetilde{p}_{n}(\underline{p})\right)>\pi_{i}^{*},
$$


which implies its profit is higher at the new equilibrium price as stated in (1).

I then just need to derive sufficient conditions for the profits of firms $1, \ldots, m$ to be higher. We will show that if $\underline{p}=p_{1}^{*}+\varepsilon$ then

$$
\pi_{i}\left(\widetilde{p}_{1}(\underline{p}), \ldots, \widetilde{p}_{n}(\underline{p})\right)>\pi_{i}^{*}, i=1, \ldots, m
$$

for $\varepsilon>0$ and sufficiently small. Wlog, consider firm 1. Given the other firms' new prices, firm 1's equilibrium profit has a lower bound associated with it pricing at $\underline{p}=p_{1}^{*}+\varepsilon$ :

$$
\pi_{1}\left(\widetilde{p}_{1}\left(p_{1}^{*}+\varepsilon\right), \ldots, \widetilde{p}_{n}\left(p_{1}^{*}+\varepsilon\right)\right) \geq \pi_{1}\left(p_{1}^{*}+\varepsilon, \widetilde{p}_{2}\left(p_{1}^{*}+\varepsilon\right), \ldots, \widetilde{p}_{n}\left(p_{1}^{*}+\varepsilon\right)\right) .
$$

Given $\widetilde{p}_{i}\left(p_{1}^{*}+\varepsilon\right) \geq p_{1}^{*}+\varepsilon(=p)$ for $i=2, \ldots, m$ and firm 1's profit is increasing in rival firms' prices, it follows that

$$
\begin{aligned}
& \pi_{1}\left(p_{1}^{*}+\varepsilon, \widetilde{p}_{2}\left(p_{1}^{*}+\varepsilon\right), \ldots, \widetilde{p}_{n}\left(p_{1}^{*}+\varepsilon\right)\right) \\
\geq & \pi_{1}\left(p_{1}^{*}+\varepsilon, \ldots, p_{1}^{*}+\varepsilon, \widetilde{p}_{m+1}\left(p_{1}^{*}+\varepsilon\right), \ldots, \widetilde{p}_{n}\left(p_{1}^{*}+\varepsilon\right)\right) .
\end{aligned}
$$

Since $\widetilde{p}_{i}(p), i=m+1, \ldots, n$, has been shown to be strictly increasing in $p$ for $p \in\left(p_{1}^{*}, p_{m+1}^{*}\right)$, there exists a differentiable, strictly increasing function $\psi_{i}\left(p_{1}^{*}+\varepsilon\right) \in\left[p_{i}^{*}, \widetilde{p}_{i}\left(p_{1}^{*}+\varepsilon\right)\right]$ which acts as a lower bound on $\widetilde{p}_{i}(\underline{p})$. (Note that we are not assured that $\widetilde{p}_{i}(\underline{p})$ is differentiable everywhere.) Given firm 1's profit is increasing in rival firms' prices, it follows that:

$$
\begin{aligned}
& \pi_{1}\left(p_{1}^{*}+\varepsilon, \ldots, p_{1}^{*}+\varepsilon, \widetilde{p}_{m+1}\left(p_{1}^{*}+\varepsilon\right), \ldots, \widetilde{p}_{n}\left(p_{1}^{*}+\varepsilon\right)\right) \\
\geq & \pi_{1}\left(p_{1}^{*}+\varepsilon, \ldots, p_{1}^{*}+\varepsilon, \psi_{m+1}\left(p_{1}^{*}+\varepsilon\right), \ldots, \psi_{n}\left(p_{1}^{*}+\varepsilon\right)\right) .
\end{aligned}
$$

Combining (2)-(4):

$$
\pi_{1}\left(\widetilde{p}_{1}\left(p_{1}^{*}+\varepsilon\right), \ldots, \widetilde{p}_{n}\left(p_{1}^{*}+\varepsilon\right)\right) \geq \pi_{1}\left(p_{1}^{*}+\varepsilon, \ldots, p_{1}^{*}+\varepsilon, \psi_{m+1}\left(p_{1}^{*}+\varepsilon\right), \ldots, \psi_{n}\left(p_{1}^{*}+\varepsilon\right)\right),
$$

so the RHS is a lower bound on firm 1's equilibrium profit when the minimum price is $p_{1}^{*}+\varepsilon$. It is then sufficient to prove that this lower bound exceeds the original equilibrium profit:

$$
\pi_{1}\left(p_{1}^{*}+\varepsilon, \ldots, p_{1}^{*}+\varepsilon, \psi_{m+1}\left(p_{1}^{*}+\varepsilon\right), \ldots, \psi_{n}\left(p_{1}^{*}+\varepsilon\right)\right)>\pi_{1}^{*} .
$$

Take the derivative of the LHS of (5) with respect to $\varepsilon$

$$
\begin{aligned}
& \frac{d \pi_{1}\left(p_{1}^{*}+\varepsilon, \ldots, p_{1}^{*}+\varepsilon, \psi_{m+1}\left(p_{1}^{*}+\varepsilon\right), \ldots, \psi_{n}\left(p_{1}^{*}+\varepsilon\right)\right)}{d \varepsilon} \\
= & \frac{\partial \pi_{1}\left(p_{1}^{*}+\varepsilon, \ldots, p_{1}^{*}+\varepsilon, \psi_{m+1}\left(p_{1}^{*}+\varepsilon\right), \ldots, \psi_{n}\left(p_{1}^{*}+\varepsilon\right)\right)}{\partial p_{1}} \\
& +\sum_{i=2}^{m} \frac{\partial \pi_{1}\left(p_{1}^{*}+\varepsilon, \ldots, p_{1}^{*}+\varepsilon, \psi_{m+1}\left(p_{1}^{*}+\varepsilon\right), \ldots, \psi_{n}\left(p_{1}^{*}+\varepsilon\right)\right)}{\partial p_{i}} \\
& +\sum_{i=m+1}^{n} \frac{\partial \pi_{1}\left(p_{1}^{*}+\varepsilon, \ldots, p_{1}^{*}+\varepsilon, \psi_{m+1}\left(p_{1}^{*}+\varepsilon\right), \ldots, \psi_{n}\left(p_{1}^{*}+\varepsilon\right)\right)}{\partial p_{i}} \frac{\partial \psi_{i}\left(p_{1}^{*}+\varepsilon\right)}{\partial \varepsilon}
\end{aligned}
$$


Evaluate at $\varepsilon=0$ :

$$
\begin{aligned}
& \frac{d \pi_{1}\left(p_{1}^{*}, \ldots, p_{m}^{*}, \psi_{m+1}\left(p_{1}^{*}\right), \ldots, \psi_{n}\left(p_{1}^{*}\right)\right)}{d \varepsilon}=\frac{d \pi_{1}\left(p_{1}^{*}, \ldots, p_{n}^{*}\right)}{d \varepsilon} \\
= & \frac{\partial \pi_{1}\left(p_{1}^{*}, \ldots, p_{n}^{*}\right)}{\partial p_{1}}+\sum_{i=2}^{m} \frac{\partial \pi_{1}\left(p_{1}^{*}, \ldots, p_{n}^{*}\right)}{\partial p_{i}}+\sum_{i=m+1}^{n} \frac{\partial \pi_{1}\left(p_{1}^{*}, \ldots, p_{n}^{*}\right)}{\partial p_{i}} \frac{\partial \psi_{i}\left(p_{1}^{*}\right)}{\partial \varepsilon} \\
= & \sum_{i=2}^{m} \frac{\partial \pi_{1}\left(p_{1}^{*}, \ldots, p_{n}^{*}\right)}{\partial p_{i}}+\sum_{i=m+1}^{n} \frac{\partial \pi_{1}\left(p_{1}^{*}, \ldots, p_{n}^{*}\right)}{\partial p_{i}} \frac{\partial \psi_{i}\left(p_{1}^{*}\right)}{\partial \varepsilon}>0
\end{aligned}
$$

because $\frac{\partial \pi_{1}\left(p_{1}^{*}, \ldots, p_{n}^{*}\right)}{\partial p_{1}}=0$ and $\frac{\partial \pi_{1}\left(p_{1}^{*}, \ldots, p_{n}^{*}\right)}{\partial p_{i}}>0$. It then follows that $\exists \varepsilon^{\prime}>0$ such that (5) is true $\forall \varepsilon \in\left(0, \varepsilon^{\prime}\right)$.

A minimum price that only binds for the lowest-priced firms is clearly beneficial to the other firms because their lower-priced rivals have raised their prices. The problematic issue is whether the lowest-priced firms are better off. Holding fixed their rival firms' prices, that is not necessarily the case (and clearly is not the case when $m=1$ ) because the lowest-priced firms are pricing above their best reply functions. Of course, the rival firms are not holding their prices fixed but instead are raising their prices because the lowest-priced firms have raised their prices. This rise in rivals' prices enhances the profits of those firms which raised their prices to the minimum level.

In conclusion, regardless of the heterogeneity of firms, if firms are sufficiently patient then they can then collude using the convention that all firms' prices respect some minimum level.

\section{References}

[1] Goto, Ujo and Toshiaki Iizuka, "Firm Heterogeneity and Cartel Sustainability: An Empirical Assessment," University of Tokyo, August 2014.

[2] Milgrom, Paul and John Roberts, "Rationalizability, Learning, and Equilibrium in Games with Strategic Complementarities," Econometrica, 58 (1990), 1255-1277. 